\title{
Sobre lágrimas, corpos e silêncios pedagógicos: transitando entre educação física escolar, sexualidades e gênero
}

\author{
About tears, bodies and silence: transiting between school physical \\ education, sexuality and gender \\ Marco Aurélio Alves e Silva \\ marcoaurelioas.ufg@gmail.com \\ Programa de Pós-graduação Interdisciplinar em Direitos Humanos da \\ Universidade Federal de Goiás, Brasil \\ Aline Nicolino \\ aline.nicolino@gmail.com \\ Faculdade de Educação Física e Dança da Universidade Federal de Goiás, Brasil
}

Recepção: 26 Junho 2020 Aprovação: 08 Setembro 2020 Publicação: 09 Outubro 2020

Cita sugerida: Alves e Silva, M. A. y Nicolino, A. (2020). Sobre lágrimas, corpos e silêncios pedagógicos: transitando entre educação física escolar, sexualidades e gênero. Educación Física y Ciencia, 22(4), e147. https:// doi.org/10.24215/23142561e147
Resumo: Este texto trata da objetificação do 'corpo gay' como diferente no contexto escolar a partir de experiências corporais vivenciadas nas séries iniciais do Ensino Fundamental, em aulas de Educação Física (EF), de uma escola particular de Goiás. Para isso, o texto divide-se em três momentos: a narrativa autobiográfica do vivido que, por sua vez, objetiva mostrar o quanto a corporeidade é uma aprendizagem coletiva e que a violência praticada pela direção, professora de EF e estudantes para significar o diferente constitui a própria condição de existência do normal; em segundo, um diálogo bibliográfico com teóricos, textos e pensamentos sobre os corpos, gêneros, sexualidades e suas diversidades; e, por último, evocando os dois anteriores, analisamos as impossibilidades nesse meio escolar. Compreendemos, com isso, que a produção do diferente na escola é uma forma de conhecimento e que o fato de não ter as temáticas gênero e sexualidade no currículo, sob a justificativa de pertencer ao âmbito privado-familiar, não impede que sejam ensinadas. Assim, ao ensinar o que não se reconhece como conhecimento, a escola negligencia humanidades e, ao mesmo tempo, não deixa de assumir a responsabilidade pedagógica que refuta e ignora. Identificamos, ao final, que as visibilidades de corporeidades emergentes não as tornam necessariamente mais compreensíveis e que uma prática pedagógica ampliada e comprometida com os direitos humanos pode possibilitar novas experimentaçóes de existência, de vidas vivíveis.

Palavras-chave: Educação Física escolar, Sexualidades, Gênero, Homofobia.

Abstract: This text talks about the objectification of the 'gay body' as different in the school context from bodily experiences lived in the early grades of Elementary School, during Physical Education (PE) classes, from a private school in Goiás. he narrative of the one who experienced it, the reading of the regulatory documents of Primary Schools in Brazil and surveying homophobic pedagogical practices aim to show how corporeality is a collective learning. In this way, the violence practiced by the head teacher, the PE teacher and the students to contain and control the 'different one' is the very condition of existence. herefore, we understand that the production of what is 'different' in school is a form of knowledge and that the fact of not having gender and sexuality subjects in the curriculum, under the justification it belongs to the private-family sphere, does not exempt schools from this responsibility. hat is, when teaching what is not recognized as knowledge, it does not assume the pedagogical responsibility that it refutes and ignores. We believe, therefore, that the visibility of emerging corporealities does not necessarily make them more understandable and that an expanded pedagogical practice, committed to human rights, can enable new experiments of existence, of living lives.

Keywords: School Physical Education, Sexualities, Gender, Homophobia, Goiás. 


\section{O que os corpos silenciados dizem sobre os silêncios pedagógicos? Notas sobre as aulas de educação física}

Este texto trata da objetificação do 'corpo gay' como 'diferente' ao relembrar as experiências corporais vivenciadas nas séries iniciais do Ensino Fundamental, em aulas de Educação Física (EF), de uma escola particular de Aparecida de Goiânia-Goiás. Localizada em uma região periférica da cidade, a escola oferecia Ensino Infantil e Fundamental, atendendo um público de classe média baixa. Por ser uma instituição de porte pequeno, as aulas de EF aconteciam no pátio, onde se hasteava a bandeira do Brasil, em comemoração de sua data, e se cantava o hino nacional na semana da pátria.

As aulas exigiam uma vestimenta própria, sendo bermuda e camiseta regata para os meninos e shorts e camiseta com mangas curtas para as meninas. A vestimenta não era a única forma de projetar as diferenças entre os corpos, a organização pedagógica ao iniciar as aulas, correndo ao redor do pátio, seguido do polichinelo ou flexão, em que somente as meninas ficavam com os joelhos no chão, 'aqueciam' a angústia para a parte central da aula. Momento em que meninas e meninos eram separados e distanciados no espaço, em uma divisão inconciliável entre os corpos e práticas corporais. $\mathrm{O}$ distanciamento comunicava não apenas a distinção dos conteúdos que seriam desenvolvidos para meninos e meninas, mas, sobretudo, a sensação de estar isolado e desprotegido no meio de indivíduos que me detestavam e me batiam às escondidas na escola.

O futebol, reconhecido naquele espaço como de domínio 'masculino', direcionado somente para os meninos, colocava em prática um pressuposto funcionamento sexo-gênero-prática heterossexual para regular as corporeidades dos meninos, sobretudo, daqueles que não ‘jogavam’ o jogo. Em tempos de Copa do Mundo, em que só se lia, escutava e via a seleção brasileira de futebol, corporeidades emergentes ganhavam maior visibilidade, assim como as formas de regulação e controle dos movimentos, de suas experimentações e de suas possibilidades de se comunicar socialmente. O compartilhamento de uma visão hegemônica, que buscava invisibilizar o que a sociedade prefere não ver (Miskolci, 2012), colocava em funcionamento uma suposta lógica entre pênisidentidade de gênero e prática sexual, para justificar as formas de violência praticada por parte dos estudantes, professora de $\mathrm{EF}$ e direção. $\mathrm{O}$ não dito sobre as discussões de gênero e sexualidade na escola, ou seja, aquilo que não se reconhecia como conteúdo curricular ${ }^{1}$, era ensinado cotidianamente em práticas pedagógicas generificadas que naturalizavam e, ao mesmo tempo, inscreviam nos corpos um conhecimento, que me objetificava como diferente. Para sobreviver naquele espaço, inventava desculpas para não ir à escola ou realizar exercícios, permanecia horas escondido no banheiro e estava sempre em vigilância. A escola nunca foi um lugar seguro para mim. A violência sempre existiu e me espreitava. 
A escola me ensinava que para tornar-se sujeito é preciso se sujeitar a ser o que não se é como condição de existência na escola. Trazer o vivido, como um recurso narrativo analítico, explora a ideia de que as experiências individuais são produtos de um conhecimento coletivo, histórico e, portanto, político sobre os corpos reconhecidos como 'diferentes'. Isto é, ao compreendermos a experiência como um conhecimento "que se expressa por meio do corpo, o que ele conhece, o que foi profundamente inscrito nele" (Hooks ${ }^{2}$, 2017, p. 122), buscamos evidenciar que a abjeção 3 é produto dos sentidos e dos significados produzidos coletivamente e esse "modo como sabemos o que sabemos" (Hooks, 2017, p. 124) também pode ser desconstruído. Narrar os sentidos experimentados na escola busca, sobretudo, tornar estranho aquilo que nos parece familiar, para que novos olhares e leituras possam ser possíveis, a partir de "interpretações colaborativas entre os autores, apresentada na primeira pessoa do plural" (Silva Junior \& Caetano, 2017, p. 42).

Dialogar com outros estudos, realizados com estudantes que vivenciaram práticas homofóbicas em seus corpos, é tornar visível os sentidos e a aprendizagem de um conhecimento que não se quer reconhecer. A leitura sobre esse saber experienciado evidencia que não há como discutir EF escolar sem pensar em sexualidades, gêneros e corpos. Não é possível deixar a sexualidade do lado de fora da escola, como bem lembra Louro (1997). Compreensão que traz o corpo como um dos dispositivos curriculares acionados pela escola para formar sujeitos, como "base onde o conhecimento é significado" (Caetano, 2013, p. 67). Conhecimento didaticamente operacionalizado a partir de um "conjunto de esforços pedagógicos desenvolvidos com intenções educativas” (Moreira \& Candau, 2007, p 18). O currículo, nesse sentido, reorganiza "a própria rede de entrelaçamentos materializante desses corpos, que mistura o global, o histórico e o situado, (...) compondo possibilidades de existência através de conexóes" (Ranniery, 2018, p. 210). Para pensar os sentidos e os significados de vidas vivíveis na escola, problematizamos: quais discursos de humanidade vêm sendo apresentados e quais vêm sendo silenciados para constituírem o currículo escolar? Questionar a representação de humanidade e suas impossibilidades de expressão se dá pelo entendimento que a produção do diferente na escola não é produto da ignorância, mas "um efeito não uma ausência - de conhecimento" (Britzman, 1996, p. 91). Apoiados, portanto, nos dizeres de César (2012,359), que "qualquer decisão teórica e epistemológica é também política, (...) pois diz respeito a processos de validação, ordenação, classificação e normalização de saberes e práticas no interior das escolas", entendemos que as escolhas afetam os corpos.

O que significa dizer que a produção do diferente, a partir da objetificação do 'corpo gay', é aqui compreendida como uma forma de conhecimento, que impõe aos indivíduos uma aprendizagem coletiva, que não é neutra e que se estrutura em preconceitos e discriminações de gêneros e de sexualidades, ensinado também na escola. E, nesse sentindo, o fato de as temáticas não estarem nas diretrizes educacionais, nos currículos de formação docente e escolar ${ }^{4}$, sob a justificativa 
de pertencerem ao âmbito privado-familiar ${ }^{5}$, não exime a escola de sua responsabilidade. Diante dessa compreensão, argumentamos que o silêncio dessas discussões no currículo é um investimento interessado em 'desconhecer' humanidades e que vem 'prejudi-educando' os corpos escolares, pois, ao não reconhecer tais temáticas como escolarizáveis, a escola e, especialmente, a EF encontram-se em uma situação paradoxal, que ensina o que não se reconhece como conhecimento e, ao mesmo tempo, refuta e desconhece o conhecimento cientificamente produzido sobre essas temáticas, não 'cumprindo' com suas responsabilidades pedagógicas.

Para sinalizar alguns desses efeitos produzidos sobre os corpos escolares, dividimos a escrita em três partes. A primeira, narrada em primeira pessoa $^{6}$, apresenta a operacionalização da produção do diferente nas aulas de Educação Física, como um investimento higiênico, balizado na lógica heteronormativa. Em seguida, analisamos a narrativa enquanto um conhecimento que possibilita compreender e questionar o quanto o emergente torna-se abjeto no processo de escolarização do silenciamento e apagamento das subjetividades e, portanto, de vidas vivíveis. Finalizamos a escrita, apresentando que ensinar pelas impossibilidades é uma forma de conhecimento que é construído nas escolas, efeito de um investimento histórico, cultural e político, que visa a silenciar e aniquilar não somente corpos emergentes, humanidades, mas também o ato pedagógico crítico, reflexivo e comprometido com a produção científica.

\section{Ser 'diferente' para existir na escola: narrativa em primeira pessoa dessa produção de conhecimento}

Confesso que cansei de chorar escondido nos banheiros do colégio após as aulas de Educação Física. Quando as desculpas não logravam mais êxito em casa, minha mãe me obrigava ir rumo ao meu suplício semanal - risadas, agressóes e mesmices sexistas que a escola me proporcionava no período vespertino. Sexistas, pois, para minha professora de EF, o único momento em que se misturavam meninos e meninas eram os minutos de aquecimento, uma espécie de prévia do meu sofrimento.

Terminada essa preliminar, era hora do abate: para os meninos, obrigatoriamente, futebol; já para as meninas, vôlei, queimada ou dança. Não havia concessões: meninos brasileiros jogam e gostam de futebol. É masculino, viril e macho querer ser um novo Fenômeno ou um Cafu. Como sempre fui gordo e avesso aos exercícios físicos, dois caminhos se abriam para mim: para o meu alívio, o banco de reservas, pois era sempre o último a ser escolhido; ou, quando jogava a contragosto, o time visivelmente insatisfeito e a professora sempre tácita, como cúmplices, me atiravam ao gol para levar sucessivas e pesadas boladas contra meu corpo.

Caso deixasse passar muitos gols a ponto de meu time ser humilhado pelo adversário, eu trocava de roupa no banheiro, após a aula, já esperando pelos socos e pontapés de punição que viriam. Nesse caso, chorava silenciosamente, já que, nesse ambiente escolar, o silêncio era a máxima e, mesmo sendo uma bicha gorda, não queria ser acusado também de 
cagueta. Menos ruidoso e doloroso, o banco de reservas era o meu objetivo, pois, uma vez deixado à margem, ficava ao lado da quadra das meninas para observá-las jogando.

Cuido para que o tom deste relato não saia um tanto quanto ressentido, pois os meus colegas apenas repetiam as lições que receberam dos que insistiam em formatar machos estereotipados, ou seja, "fazendo crer ao indivíduo que um homem se faz sob sucessivos absolutos; nunca chora; tem que ser o melhor; competir sempre; ser forte; jamais se envolver afetivamente e nunca renunciar" (Nolasco, 1993, p. 40).

Essa insistência de se formatar e reproduzir corpos, gêneros e identidades rigidamente reconhecíveis atravessa não só as pedagogias institucionais familiares, religiosas, mas principalmente as escolares. O comportamento cúmplice e tácito da minha professora, diante da violência sofrida por mim, deixa claro que "a escola reforça os estereótipos através das atividades curriculares” (Romero, 1994, p. 231).

Lembro-me de um dia que, muito cansado de sofrer tudo isso e por não querer jogar futebol, mas dançar axé ou Ragatanga ${ }^{7}$, xinguei a professora de EF num rompante de ódio e fui levado à coordenação. Ofendida, a docente relatou à coordenadora que havia sido humilhada por mim na frente dos demais estudantes e que eu, por pouco, quase a agredi. Contrariando o protocolo de suspensão, a coordenadora me advertiu que, mesmo sendo diferente, eu teria que aprender a me controlar e respeitar as regras. Não havia o que fazer, pois, de acordo com ela, "a vida é assim". E me deixou ir com a certeza de que, se tudo desse certo, eu me calaria por medo de uma futura suspensão e, enfim, seria um pouco mais normal.

Para ela, ou seja, para a escola, as regras da vida consistiam em não desrespeitar as autoridades e agir como um homem, ou seja, jogar futebol com os demais garotos. Dessa maneira, a escola, sendo "microssistema da sociedade que exerce influências sobre os agentes que socializam nesse campo, e suas identificações sociais" (Dias \& Cruz, 2015, p. 34), me coagia a cumprir a cartilha disciplinar da normalidade binária de gênero. Ou seja, as disciplinas escolares e suas técnicas silenciavam, puniam e marcavam o meu corpo e identidade a seguirem, para o bem de todos, um caminho heteronormativo.

Dessa maneira, a escolarização, “ao oferecer representações de versões socialmente normalizadas do adulto e da criança, da mulher e do homem" (Britzman, 1996, p. 78), se junta à família e comunidade e confundem propositadamente o que vem a ser sexo e gênero. Essa confusão dá espaço à noção social e majoritária que enxerga as diferenças biológicas/corporais como fronteiras incontornáveis e compulsórias para as identidades e nomeações que um homem ou uma mulher recebem:

A ligação entre sexo e gênero é uma consequência política do controle dos corpos: definem-se as características do que é feminino, mas percebe-se, assim como se percebia na definição do que seria mulher, por exemplo, que muitos corpos não se encaixam nem numa categoria nem na outra. Muitos comportamentos culturais de homens e mulheres não se encaixariam na descrição hegemônica de masculino e feminino. Isso realmente é um problema político grave, porque, como se trabalha a questão do poder, se se continuam excluindo determinados corpos? (Pinto, 2004, p. 40). 
Para impedir a rebeldia desses corpos insurgentes, os quais se recusam a cumprir as 'regras da vida normal', é necessário que o corpo seja educado a partir de um discurso de poder que lhe transmita e imprima a normalidade binária que deixa à margem aqueles que escapam da lógica dual de se pensar gênero e sexualidade. Ao me negar reconhecimento, a escola e os meus colegas me ensinavam, mesmo que à custa de duras penas, que amotinados são, pegando emprestado um termo desenvolvido por Foucault (2001), anormais que devem ser consertados.

Carregando consigo fortes traços disciplinares, a escola reproduzia, por meio de suas atividades, uma verdade a ser acreditada e jamais questionada. Verdade essa totalmente ligada à noção de poder "que está sempre intrincado em qualquer relação" (Veiga-Neto, 2008, p. 24). Verdade essa que acuava o meu corpo e meus desejos de desobedecer aos comandos da minha professora e dançar com as meninas. Verdade essa que é tão somente um "conjunto de procedimentos que permitem a cada instante e a cada um pronunciar enunciados que serão considerados verdadeiros" (Foucault, 2006, p. 233).

Não importava quantos socos e pontapés meu corpo sofria às escondidas ou não. As marcas, o silêncio e a advertência me diziam qual era a verdade a ser acatada: se tenho um pênis, sou um homem e devo agir como um. Para dar conta disso, nesse caso, a escola e a educação física agem como "instituições que (re)produzem um saber-poder que tem como alvo o homem, que ao mesmo tempo é efeito e objeto desse investimento" (Zoboli, 2012, p. 17).

Uma vez dominado, o corpo educado desse homem deve ser disciplinado, ou seja, submetido e docilizado, colocado "numa maquinaria de poder que o esquadrinha, o desarticula e o recompõe" (Foucault, 2014, p. 135). Essas disciplinas impostas "funcionam como códigos de permissão e interdição" (Veiga-Neto, 2008, p. 26) que traduzem as regras que todos devem seguir - meninos devem ser machos e futuros Fenômenos. Enquanto as meninas podiam brincar de queimada, vôlei ou dança.

A manutenção desse olhar binário e confuso para gênero e sexualidade carrega a ideia de que há uma noção preexistente para os gêneros e sexos, ou melhor: haveria comportamentos naturais para os homens e outros para as mulheres. Tese essa que é negada pelos estudos queer de Butler (2015, p. 42, grifo da autora):

O gênero é uma complexidade cuja totalidade é permanentemente protelada, jamais plenamente exibida em qualquer conjuntura considerada. Uma coalizão aberta, portanto, afirmaria identidades alternativamente instituídas e abandonadas, segundo as propostas em curso; tratar-se-á de uma assembleia que permita múltiplas convergências e divergências, sem obediência a um telos normativo e definidor.

Essa lógica de um gênero construído permanentemente numa conquista de reconhecimento identitário plural ratifica a noção de que a identidade do sujeito deve ser lida como "fluida, parcial, contraditória, não-unitária, uma noção que veja a identidade como envolvendo elementos sociais" (Britzman, 1996, p.73). Portanto, de acordo com 
Louro (1997), não faz muito sentido que existam identidades de gênero e sexualidades fixas, perenes. Assim como o gênero, as identidades, os corpos, as sexualidades, estão em constante transformação.

Nessa direção, o corpo deve ser traduzido como sendo resultado de "uma multiplicidade de fluxos de signos que nos atravessam" (Zoboli, 2012, p. 65) e é constantemente implicado pela/e na cultura, de acordo com Santaella (2004). Logo, mesmo que meu corpo tenha sido "treinado no silêncio e em determinado modelo de fala" (Louro, 2001, p. 26), a lógica de uma práxis sexista do currículo da Educação Física pouco se sustenta ao considerar que sou plural, assim como meu corpo e identidade.

\section{Escolarizando as diferenças: problematizando os sentidos e o significado do 'diferente' nas aulas de Educação Física}

Assim, entre narrativas e estratégias de sobrevivência, questionamos: o que pode um corpo diferente nas aulas de EF escolar? O suor, as lágrimas e os silêncios descrevem sentidos elaborados pelo vivido nas aulas de EF, em que existo a partir do diferente, para pensar, tecer e cruzar "os fios de experiências e o tempo, que ficaram momentaneamente 'apagadas' no e com o tempo, mas que foram reencontradas a partir dos diálogos" desta escrita (Silva Junior \& Caetano, 2017, p. 42). Aprendemos entre regulações e interdições, que existir nessa condição limitava não apenas a minha corporeidade, mas as possibilidades de vidas vivíveis naquele espaço. O exame constante da professora sobre os corpos escolares, "corrigindo a conduta, a postura física, seu corpo", fazia parte de um conhecimento, "sob o ponto de vista da sexualidade, restritamente heterossexual” (Louro, 1997, p. 75-76), que buscava adequar a corporeidade a supostos gestos, comportamentos e atitudes 'próprios' de meninas e de meninos. A heterossexualidade torna-se, nesse contexto, o dispositivo ${ }^{8}$ utilizado para identificar, nomear e reiterar as identidades normais, produzindo sentidos e acionando diversas engrenagens para colocar em funcionamento um conhecimento que atribui ao sexo compreendido como um “'dado' anterior à cultura, de caráter imutável, a-histórico e binário" (Louro, 2008, p. 15) - a condição de significar e dar legitimidade as impossibilidades corporais.

Práticas pedagógicas cotidianas informavam quais linguagens corporais eram possíveis naquele espaço, ensinando o que rejeitar e o que desprezar. Assim, o 'diferente' é produzido em "um processo temporal que atua através da reiteração de normas” (Butler, 2001), que diz, muitas vezes sem dizer, como cada corpo deve se comportar, agir e pensar não apenas nas aulas de EF, mas na forma de vestir, sentar, mover, falar, gesticular, comer, ou seja, no uso de sua linguagem corporal. Aprendemos, com isso, que há uma educação do corpo ${ }^{9}$ normal sendo produzida reiteradamente a partir do que se institui como 'diferente' na escola, informada por "normas regulatórias pelas quais a diferença sexual é materializada” (Butler, 2001, p. 156).

$\mathrm{O}$ que significa dizer que, ao dar inteligibilidade ao funcionamento sexo-gênero e prática sexual, a EF assume a responsabilidade de educar 
a partir de uma visão restrita e interessada de humanidade, pautada na lógica hegemônica heterossexual, que, apesar de não estar posta no currículo, é ensinada cotidianamente, ao restringir e, por vezes, impossibilitar a própria vivência e exploração da corporeidade. Isto é, ao negligenciar um conhecimento próprio da cultura corporal ${ }^{10}$, objeto de reflexão e estudo do campo, a EF dá limites aos corpos e ao conhecimento que produz. Mais do que isto, ela invisibiliza, repreende e silencia corporeidades ao não as reconhecer enquanto humanidades. Ao ensinar pelas impossibilidades corporais, por meio da contenção e da interdição, a EF deslegitima a produção científica em gênero e sexualidade, dessubstancializando os "sentidos histórico, socioantropológico e político" (Gonçalves \& Mello, 2017, p. 28) da cultura corporal. Isto é, a EF caminha na contramão de seus princípios de promover a "liberdade de expressão dos movimentos, emancipação", por meio da "reflexão pedagógica ampliada e comprometida(...), que busca ultrapassar o senso comum e construir formas elaboradas de pensamento" (Coletivo de Autores, 1992, p. 17-28). Compreendemos, portanto, que, ao educar os corpos por meio de discursos e práticas que não reconhece como conhecimento curricular, a EF se distancia de sua atribuição pedagógica de compreender os sentidos e os significados produzidos historicamente nos e pelos corpos, restringindo e, por vezes, impossibilitando corporeidades, humanidades e, consequentemente, vidas vivíveis.

A narrativa do vivido em aulas de EF possibilita identificar que ignorar ou silenciar-se perante conhecimentos que constituem nossa humanidade também exerce uma função pedagógica. De tal modo, que tanto as intervenções ditas, mas, também as não ditas, silenciadas pelo consentimento da violência ${ }^{11}$ posta em deboches, piadas, xingamentos, apelidos, ridicularização e exclusão do grupo, constituem formas de violência vivenciadas nas e pelas práticas corporais durante as aulas. Entendemos, portanto, que o silêncio da professora "organiza um determinado tipo de ordenamento 'pedagógico', ao consentir com a naturalização de uma lógica heterossexual, ora operacionalizada na invisibilidade e/ou repulsa homossexual, ora projetada na inferioridade atribuída ao feminino", sendo a falta uma estratégia eficiente para escolarizar a sexualidade na EF (Nicolino \& Paraíso, 2018, p. 101). O exercício permanente da impossibilidade corporal e o consentimento de práticas de violência, que visam a exterminar corpos emergentes, apresentam-se como meios de educar 'interessados' no apagamento e na homogeneização dos corpos. $O$ que significa pensar que o desconhecimento é entendido, nos termos de Britzman (1996), como produto de um efeito, que conforma uma pedagogia da omissão acadêmica e da conivência com a violação de humanidades.

É sobre essa estratégia, de se educar o corpo por meio das impossibilidades corporais e do silêncio, para conformar o 'corpo gay' como 'diferente', que queremos problematizar, por entendermos constituir alguns dos sentidos e dos significados de uma aprendizagem coletiva sobre a corporeidade, que não reside somente nos limites 
estruturais e pedagógicos da escola. Essa aprendizagem compreendida como histórica, social e, por isso, política, parte de uma leitura cultural contemporânea que cultua a publicização do físico, de forma exacerbada, e projeta a gestão do "músculo como um modo de vida", por meio de uma racionalidade técnica sustentada pelo "desejo de obter tensão máxima da pele; o amor pelo jovem; ansiedade frente a tudo o que na aparência pareça enrugado, amolecido" (Courtine, 1995, p. 85-86). A EF, nesses termos, informa de modo 'eficiente' e pragmático "um ideal de saúde, produzida pela lógica de melhor rendimento físico e de conhecimentos especializados constituídos de técnicas objetivas, reforçando a absolutização da vida física, (...) desconsiderando, sobretudo, as subjetividades humanas e as diferenças étnicas e culturais" (Silva, 2001, p. 20 e 30). A contestação dessas linguagens nos leva a questionar: Quanto mais 'saudáveis' somos, melhor somos controlados ${ }^{12}$ ? O que estamos entendendo por corpo saudável? A saúde nos é apresentada como sinônimo de eficácia? As perguntas buscam problematizar as tramas de saber-poder investidas para tornar inteligível os corpos em nossa sociedade, mais do que isto, para pensar sobre a responsabilidade da EF que ao colocar em funcionamento uma suposta lógica de coerência entre o sexo-gênero-prática heterossexual (Altmann, 1998; 2001; Goellner, 2003; Romero, 1994; Soares, 2001), diz sem dizer sobre uma determinada 'racionalidade' atribuída ao 'normal', em que diferenças biológicas são utilizadas para justificar desigualdades corporal, moral e social. Essa lógica é produzida e conformada por meio de uma educação moral higiênica, oficializada pela EF desde sua entrada no campo escolar, no início do século XX no Brasil, em que o corpo é educado nas ideias de hierarquia, ordem, disciplina, higiene e esforço individual (Soares, 2001).

Apesar dessa racionalidade ter sido alvo de críticas no campo acadêmico, sobretudo, nos anos de $1990^{13}$, entendemos que ainda há uma compreensão social e política demandando da EF uma pedagogia do rendimento e da execução técnica, como "repetição estilizada de certos (...) gestos corporais, movimentos e ações de vários tipos, para formar a ilusão de um EU”' (Butler, 2019, p. 214), produzindo uma 'ontologia' do ser, em que a eficiência dos gestos, a precisão dos movimentos, a força, a velocidade e as habilidades técnicas constituem algumas ideias de gênero e sexualidade que reificam e naturalizam uma civilidade técnica biológica. Essa compreensão só é possível, segundo Butler (2019, p. 218), pelo fato de os corpos serem reconhecidos somente "pela sua aparência atribuída de gênero". Por isso, como sugere a autora, é significativo "entender de que maneira acontece essa atribuição de gêneros aos corpos”, ou seja, esse modo de dar inteligibilidade aos corpos. A busca em reforçar uma noção de neutralidade, pela lógica de melhor rendimento físico mostra o quanto há uma ficção social presente e convincente na reprodução de um 'masculino universal' ${ }^{14}$ profundamente enraizada e sedimentada nos campos esportivo e social. Contexto que também pode ser expandido para a EF escolar, que ao operacionalizar com uma perspectiva biológica para "transformar a saúde em capacidade objetivável de rendimento" (Silva, 
2001, p 21), agencia a corporeidade de meninos e meninas de forma simplista, quantificável e universal.

Essas restrições impostas aos corpos valem-se de linguagens técnicas homogeneizantes para colocar em funcionamento um suposto "masculino" universal no esporte. De tal forma, que "o homem seu corpo e seu comportamento - é o modelo a partir do qual o corpo e o comportamento da mulher são julgados, estigmatizando aquelas que ultrapassam os limites que convencionalmente lhe foram impostos" (Goellner, 2005, p. 148). Essa lógica, conforma uma inspeção sobre a sexualidade de mulheres que demonstram força, velocidade e resistência equivalentes aos homens, por exemplo, pela suspeita de ser um 'homem', demandando-as por exemplo teste de feminilidade (Devide, 2005).

O investimento e a veiculação histórica do corpo 'masculino' como modelo de um corpo esportivo possibilitam compreender alguns dos interesses e da lógica operacionalizados para colocar em funcionamento formas de manutenção e reprodução de sistemas de opressão, que se dão por um “'fazer' que obedece a certas sanções e prescrições, não sendo um processo puramente individual, mas que existe desde antes de nós existirmos" (Butler, 2019, p. 222 e 224). De modo que a generificação das práticas só é possível enquanto estiver sendo performada e, nesse sentido, voltamos a questionar sobre as impossibilidades: Por que a nomeação de um corpo como 'diferente' é tão convincente em meninos que não gostam e/ou com poucas habilidades no futebol? ${ }^{15}$. Por que a insistência na existência de uma essência entre sexo-gênero e prática corporal para dar inteligibilidade as corporeidades? (Dornelles, 2013; Silvestrin, 2013). Qual o interesse em desconsiderar as subjetividades como conhecimento e, ao mesmo tempo, ensiná-las pedagogicamente?

As questões visam a trazer para o debate o quanto as corporeidades de meninos reconhecidos como 'afeminados' são violentamente objetificadas como 'diferente' nas aulas, passando por um processo pedagógico permanente de nomeação, regulação e interdição para manter-se na condição de anormal. Tais ensinamentos podem ser lidos em diferentes produções científicas, em que corpos emergentes recorrem a várias estratégias para escapar da experiência corporal, que torna-se cada vez mais aversiva a cada aula (Santos, 2008), em que mecanismos homofóbicos são operacionalizados, reforçando ou silenciando tais condutas (Anjos, 2015; Jaeger \& Venturini \& Oliveira \& ValdíviaMoral \& Silva, 2019; Prado \& Ribeiro, 2016; Prado, 2017; Rodrigues, 2018), produzindo ambientes pouco seguros e, consequentemente, o desinteresse e o distanciamento das vivências corporais (Cunha Junior \& Melo, 1996). Contudo, essas ações são apenas alguns dos efeitos produzidos pelas impossibilidades que corpos reconhecidos como diferentes enfrentam nas aulas de $\mathrm{EF}$, ao expor uma corporeidade não reconhecida como 'masculina' (Brito \& Santos, 2013; Dornelles, 2013; Kropeniscki \& Costa, 2013; Moraes e Silva, 2008; Welzer-Lang, 2001).

$\mathrm{O}$ efeito pedagógico mais devastador é escolarizar tais sentidos e significar as corporeidades emergentes como abjetos. Compreendemos, 
por meio de lágrimas, silêncios e opressões que há um projeto de educação do corpo em vigência que visa ignorar, de forma interessada e, por isso, não neutra, a condição de existência de alguns corpos. Existir nesses termos, ou melhor, na falta deles, não diz apenas sobre qual conhecimento a escola terá possibilidade de trabalhar, mas, sobretudo, que o 'diferente' não vem se sujeitando às impossibilidades impostas. É preciso trazer, ainda, que o conhecimento inscrito no corpo produz agenciamentos que não se conformam com a estreiteza da vida e que, mesmo diante das restrições, "os currículos carregam consigo um arquivo composto de transformações improváveis das condições de estar vivo" (Ranniery, 2018, p. 215). Entendemos, ao final, que o investimento do silenciamento e do apagamento dos corpos emergentes é também a voz pulsante da experiência e do saber "que dela deriva, quando apropriar-se de sua própria vida” (Bondía, 2002, p. 27), de vidas vivíveis.

\section{Considerações Finais}

A escrita deste texto, que recorre inicialmente à narrativa em primeira pessoa, para descrever a experiência do vivido nos primeiros anos do Ensino Fundamental, de uma escola particular de Aparecida de Goinia/ GO, explora a produção de um aprendizado pedagógico comunicado, aparentemente, pela linguagem corporal nas aulas de EF, sentida pela dor e pelo desprezo e significada no corpo reconhecido como diferente. A imprecisão de uma comunicação nica, ou seja, somente pela intervenção docente, e que seja projetada de forma individual é levantada ao identificar que a educação do corpo experimentada estava alinhada à lógica de regulação e punição da direção e com as formas de violência praticadas por outros estudantes da escola, assim como pelas vivências compartilhadas em outros estudos que tratam de práticas homofóbicas em outras instituições, cidades e regióes do Brasil. Definitivamente, compreendemos que a produção do 'diferente' significado nos 'corpos gays' é produto de um efeito interessado, não neutro, de um conhecimento coletivo, histórico e político.

Trazer o valor da experiência individual como um conhecimento que busca questionar as parcialidades, é aprender com Hooks (2017), que, de longa data, nos ensina que nenhuma educação é politicamente imparcial, e que uma prática pedagógica crítica busca abraçar "a experiência, as confissóes e os testemunhos como modos de conhecimento válidos, como dimensóes importantes e vitais de qualquer processo de aprendizado" (Hooks, 2017, p. 120). Aprendemos que, tanto em épocas de Copa, quanto hoje e sempre, não podemos baixar a guarda, pois a educação, além de ser um campo de disputa de discursos, saberes e verdades como prática de liberdade nos convida diariamente a (re)conhecer, acolher, reivindicar e agir pelo reconhecimento de vidas vivíveis, visto que o 'outro', apresentado como adversário, é apenas mais um em busca de sua humanidade. A experiência do vivido e de outras vivências, expressas em outros trabalhos, mostra que a visibilidade de corporeidades emergentes incomoda e tensiona a lógica heterossexista, 
mas não as torna necessariamente mais compreensíveis, sobretudo, em ambientes onde práticas hegemônicas, sexista e homofóbicas, encontramse institucionalizadas. E, nesse sentido, o espaço escolar torna-se alvo e, ao mesmo tempo, centro da discussão e do enfrentamento das impossibilidades de vidas vivíveis, sendo a prática pedagógica crítica e comprometida com os Direitos Humanos uma estratégia potente para ampliar o conceito de humanidade.

Nesse ínterim, a urgência do outro se impõe à medida que o reconhecimento é um direito vital e incontornável (Honneth, 2003). Assim, ao nos colocarmos como contrários à invisibilização do 'diferente', compreendemos que o currículo também deve proporcionar caminhos para o (re)conhecimento de todas as pluralidades que existem, insistem e resistem no espaço não somente escolar, mas social. Mais do que isso, compreendemos ser pungente retomar a premissa freiriana de se humanizar, no sentido de viabilizar a existência daquela/e que ocupa, por ora, um lugar de oprimida/o, excluída/o, marginalizada/o (Freire, 2005). Aprendemos, ao final, que educar para a impossibilidade e sujeição é negligenciar humanidades, já que a educação da contenção visa marginalizar, isolar e silenciar os que não suportam mais chorar. $\mathrm{O}$ que significa dizer, agora na voz de docente, que ensinar pelas impossibilidades e pelo silenciamento é uma forma de conhecimento que vem educando os corpos nas escolas, efeito de um investimento histórico, cultural e político, que visa a silenciar e exterminar não somente corpos emergentes, humanidades, mas também o ato pedagógico crítico, reflexivo e comprometido com a produção científica. O que significa dizer que ensinar mesmo o que não se reconhece como conhecimento, não nos isenta da responsabilidade pedagógica.

\section{Referências}

Alliatti, A. (2014). Homossexualidade no esporte: Brasil mantém futebol dentro do armário. GloboEsporte, Rio de Janeiro. Disponível em: http://globoesporte.globo.com/futebol/noticia/2014/02/homossex ualidade-no-esporte-brasil-mantem-futebol-dentro-do-armario.html.

Altmann, H. (1998). Rompendo fronteiras de gênero: Marias [e] homens da Educação Física. 1998. 110 f. Dissertação (Mestrado em Educação) Faculdade de Educação, Universidade Federal de Minas Gerais, Belo Horizonte.

Altmann, H. (2001). Orientação sexual nos Parâmetros Curriculares Nacionais. Revista Estudos Feministas, 9(2), 575-585. Disponível em: https://www.scielo.br/scielo.php?pid=S0104-026X200100020001 $4 \&$ script $=$ sci_abstract\&tlng=pt.

Anjos, L. A. (2015). "Vôlei masculino é para homem": representações do homossexual e do torcedor a partir de um episódio de homofobia. Movimento, Porto Alegre, 21(01), 11-24.

Bandeira, G. A. (2016). “A homofobia no futebol é um problema novo?”. In: Manera, D. M. S. (orga.). Relatório anual da discriminação racial no futebol. Observatório da Discriminação Racial do Esporte, Escola de Educação Física, Fisioterapia e Dança/UFRGS, Porto Alegre. Disponível 
em: https://observatorioracialfutebol.com.br/Relatorios/2016/RELAT ORIO_DISCRIMINCACAO_RACIAL_2016.pdf

Bondía, J. L. (2002). Notas sobre a experiência e o saber de experiência. Revista Brasileira de Educação, 19, 20-28. Disponível em: https://www.scielo.br/ $\mathrm{pdf} / \mathrm{rbedu} / \mathrm{n} 19 / \mathrm{n} 19 \mathrm{a} 02 . \mathrm{pdf}$

Borrillo, D. (2010). Homofobia: história e crítica de um preconceito. Belo Horizonte: Autêntica Editora.

Brasil. (1997). Parâmetros curriculares nacionais: introdução aos parâmetros curriculares nacionais. Secretaria de Educação Fundamental - Brasília: MEC/SEF. Disponível em: http://portal.mec.gov.br/seb/arquivos/pdf/l ivro01.pdf.

Brito, L. T. \& Santos, M. P. (2013). Masculinidades na Educação Física escolar: um estudo sobre os processos de inclusão/exclusão. Revista Brasileira de Educação Física e Esporte, São Paulo, 2(27), 235-246. Disponível em: http ://www.revistas.usp.br/rbefe/article/view/58564.

Britzman, D. P. (1996). O que é esta coisa chamada amor: identidade homossexual, educação e currículo. Educação e Realidade. 21(1), 71-96. Disponível em: https://seer.ufrgs.br/educacaoerealidade/article/view/71 644.

Butler, J. (2001). Corpos que pesam: sobre os limites discursivos do 'sexo'. In: Louro, G. (orga). O corpo educado: pedagogias da sexualidade. (2 ed., pp. 151-172). Belo Horizonte: Autêntica.

Butler, J. (2015). Problemas de gênero: feminismo e subversão da identidade. 8. ed. Rio de Janeiro: Civilização Brasileira.

Butler, J. (2019). Atos performáticos e a formação dos gêneros: um ensaio sobre fenomenologia e teoria feminista. In: Hollanda, H. B. (orga.). Pensamento feminista: conceitos fundamentais. (pp. 213-230). Rio de Janeiro: Bazar do Tempo.

Caetano, M. (2013). Movimentos curriculares e a construção da heteronormatividade. In: Rodrigues, A. \& Barreto, M. A. S. C. (orgs). Currículo, gêneros e sexualidades: experiências misturadas e compartilhadas. (pp. 63-82). Vitória/ES: Edufes.

Castellani Filho, L. (1994). Educação física no Brasil: a história que não se conta. 4 ed. Campinas: Papirus.

César, M. R. de A. (2012). A diferença no currículo ou intervenções para uma pedagogia. ETD - Educação Temática Digital, Campinas, 14(1), 351-362. Disponível em: https://periodicos.sbu.unicamp.br/ojs/index.php/etd/ar ticle/view/1257.

Coletivo de autores. (1992). Metodologia do ensino da Educação Física. São Paulo: Cortez.

Courtine, J. J. (1995). Os Stakanovistas do Narcisismo. In: Sant'anna, D. B. de. Políticas do Corpo. (p. 81-114). São Paulo: Estação Liberdade.

Cunha Junior, C. F. \& Melo, V. A. (1996). Homossexualidade, educação física e esporte: primeiras aproximações. Movimento, 3(5), 18-24. Disponível em: https://seer.ufrgs.br/Movimento/article/view/2229/937.

Devide, F. P. (2005). Gênero e mulheres no esporte: história das mulheres nos Jogos Olímpicos Modernos. Ijuí: Ed. Unijuí.

Devide, F. P. (2020). Livro CBCE 2020. Estudos de gênero na Educação Física brasileira: entre ameaças e avanços, na direção de uma pedagogia queer. 
In: Wenetz, I. \& Athayde, P. \& Lara, L. (Orgs.). Gênero e sexualidade no esporte e na educação física [recurso eletrônico]. (pp. 91-106). Natal: Edufrn.

Dias, A. F. \& Cruz, M. H. S. (2015). A produção/reprodução do corpo generificado na escola. Cad. Pes., 22(3), 25-41 Disponível em: https://www.periodicoseletronicos.ufma.br/index.php/cadernosdep esquisa/article/view/3295/2215

Dornelles, P. G. (2013). A (hetero)normalização dos corpos em práticas pedagógicas da Educação Física escolar. 2013. 193 folhas. Tese (Doutorado em Educação) - Faculdade de Educação. Programa de Pós-Graduação em Educação, Porto Alegre.

Foucault, M. (1979). Microfísica do Poder. 19 ed. Rio de Janeiro: Graal.

Foucault, M. (2001). Os anormais: curso no Collège de France (1974 - 1975). São Paulo: Martins Fontes.

Foucault, M. (2004). Ética, sexualidade, política. Coleção Ditos e Escritos V. Rio de Janeiro: Forense Universitária.

Foucault, M. (2006). Estratégia, poder-saber. Coleção Ditos e Escritos IV. 2 ed. Rio de Janeiro: Forense Universitária.

Foucault, M. (2014). Vigiar e punir: nascimento da prisão. 42 ed. Petrópolis: Vozes.

Franzini, F. (2005). Futebol é "coisa para macho"? Pequeno esboço para uma história das mulheres no país do futebol. Revista Brasileira de História. São Paulo, 25(50), 315-328. Disponível em: https://www.scielo.br/scielo.ph p? script $=$ sci_arttext\&pid $=$ S0102-01882005000200012.

Freire, P. (2005). Pedagogia do oprimido. 46 ed. Rio de Janeiro: Paz e Terra.

Ghiraldelli Junior, P. (1989). Educação física progressista: a pedagogia críticosocial dos conteúdos e a Educação Física brasileira, São Paulo: Loyola.

Goellner, S. V. (2003). Bela, maternal e feminina: imagens da mulher. Ijuí: Unijuí.

Goellner, S. V. (2005). Mulheres e futebol no Brasil: entre sombras e visibilidades. Revista Brasileira de Educação Física e Esportes. São Paulo, 19(2), 143-151.

Gonçalves, E. \& Mello, L. (2017). Gênero - vicissitudes de uma categoria e seus "problemas". Ciência e Cultura, São Paulo, 69(1), 26-30. Disponível em: http://cienciaecultura.bvs.br/scielo.php?script $=$ sci_arttext\&pid $=S 0$ 009-67252017000100012.

Gonçalves, E. \& Pinto, J. P. \& Borges, L. (2013). Imagens que falam, silêncios que organizam: sexualidade e marcas de homofobia em livros didáticos brasileiros. Curriculo sem Fronteiras, 13(2), 35-61.

Honneth, A (2003). Luta por reconhecimento: a gramática moral dos conflitos sociais. São Paulo: Editora 34.

Hooks, B. (2017). Ensinando a transgredir. a educação como prática da liberdade. 2 ed. Trad. Marcelo Cipolla. São Paulo: Editora WMF Martins Fontes.

Jaeger, A. A. \& Venturini, I. V. \& Oliveira, M. C. de \& Valdívia-Moral, P. \& Silva, P. (2019). Formação profissional em Educação Física: homofobia, heterossexismo e as possibilidades de mudanças na percepção dos(as) estudantes. Movimento, Porto Alegre, 25. Disponível em: https://seer.ufr gs.br/Movimento/article/view/88681/53084. 
Kropeniscki, F. B. \& Costa, M. R. F. (2013). Homofobia mascarada: reflexões sobre discursos discentes. Seminário Internacional Fazendo Gênero 10. ANAIS ELETRÔNICOS, Florianópolis. Disponível em: http://www.fg2013.wwc2017.eventos.dype.com.br/resources/anais/ 20/1381507863_ARQUIVO_FernandaBattagliKropeniscki.pdf

Louro, G. L. (1997). Gênero, sexualidade e educação: uma perspectiva pósestruturalista. 6. ed. Rio de Janeiro: Vozes.

Louro, G. L. (2008). Gênero e sexualidade: pedagogias contemporâneas. ProPosiçôes. 19(2), 17-23. Disponível em: https://www.scielo.br/pdf/pp/v19 n2/a03v19n2.pdf.

Louro, G. L. (2001). Pedagogias da sexualidade. In: Louro, G. L. (Org.). O corpo educado: pedagogias da sexualidade. 4. ed. Belo Horizonte: Autêntica Editora.

Medina, J. S. (1986). A educação física cuida do corpo e... "mente": bases para a renovação e transformação da Educação Física. Campinas: Papirus.

Mendes, M. I. B. de S. \& Nóbrega, T. P. (2009). Cultura de movimento: reflexões a partir da relação entre corpo, natureza e cultura. Pensar a Prática, 12(2). Disponível em: https://doi.org/10.5216/rpp.v12i2.6135.

Miskolci, R. (2012). Teoria queer: um aprendizado pelas diferenças. 2 ed. Belo Horizonte: Autêntica.

Moreira, A. F. B. \& Candau, V. M. (2007). Currículo, conhecimento e cultura. In: __. Indagaçôes sobre curriculo: currículo, conhecimento e cultura. Brasília: Ministério da Educação, Secretaria de Educação Básica.

Moraes e Silva, M. (2008). Entre a ilha deserta e o arquipélago: mapeamentos e cartografias das percepções de professores(as) sobre as masculinidades produzidas nas aulas de Educação Física. 215 f. Dissertação (Mestrado em Educação). Universidade Federal do Paraná, Curitiba.

Nicolino, A. (2018). Gênero nos currículos da formação docente em Educação Física no Brasil. In: Marlucy A. P. e Caldeira, M. C. S. (Orgas.). Pesquisas sobre curriculos, gêneros e sexualidades. (pp. 73-92). Belo Horizonte: Mazza.

Nicolino, A. \& Paraíso, M. (2018). Escolarização da sexualidade: o silêncio como prática pedagógica da Educação Física. Movimento. Porto Alegre, 24(1), 93-106.

Nicolino, A. (2020). "Posso falar?" A profilaxia pedagógica e a desordem dos gêneros! Um estudo sobre os discursos produzidos no campo da Educação Física. In: Wenetz, I. \& Athayde, P. \& Lara, L. (Orgs.). Gênero e sexualidade no esporte e na educação física [recurso eletrônico]. Natal: Edufrn.

Nolasco, S. (1993). O mito da masculinidade. Rio de Janeiro: Rocco.

Observatório. (2018). 16 homens gays e bis contam como é sua relação com futebol. Observatório da discriminação racial no futebol, 02 de junho de 2018. Disponível em: https://observatorioracialfutebol.com.br/16-home ns-gays-e-bis-contam-como-e-sua-relacao-com-futebol/

Pinto, J. P. (2004). Os gêneros do corpo: para começar a entender. In: Gonçalves, E. (Org.). Desigualdades de gênero no Brasil: reflexões e experiências. Goiânia: Grupo Transas do Corpo. 
Prado, V. M. \& Ribeiro, A. I. M. (2016). Escola, homossexualidades e homofobia: rememorando experiências na Educação Física escolar. Revista Reflexão e Ação, Santa Cruz do Sul, 24(1), 97-114.

Prado, V. M. (2017). Entre queerpos e discursos: normalização de condutas, homossexualidades e homofobia nas práticas escolares da Educação Física. Práxis Educativa, Ponta Grossa, 12(2), 501-519.

Preciado, P. (2020). Aprendiendo del virus. El Pais, 28 de março de 2020. Disponível em: https://elpais.com/elpais/2020/03/27/opinion/158531 6952_026489.html

Ranniery, T. (2018). Manifesto Beyoncé no currículo: a força da música e o brilho erótico do corpo que dança. In: Marlucy A. P. e Caldeira, M. C. S. (Orgas.). Pesquisas sobre curriculos, gêneros e sexualidades. (pp. 199-218). Belo Horizonte: Mazza.

Rodrigues, A. P. (2018). “Que time é teu?”: um debate sobre homofobia nas aulas de Educação Física. In: Rodrigues, A. P. (Org.). Educação Física na Escola Básica: debates contemporâneos. (pp. 113-136). Porto Alegre, RS: Editora Fi.

Rodrigues, A. P. (2017). A homofobia nas aulas de Educação Física: com a palavra os alunos. Lecturas: Educación Física y Deportes, Buenos Aires, 22(228). Disponível em: https://www.efdeportes.com/efd228/a-homofo bia-das-aulas-de-educacao-fisica.htm.

Romero, E. (1994). A educação física a serviço da ideologia sexista. Revista Brasileira de Ciências do Esporte, 15(3), 226-234.

Santaella, L. (2004). Corpo e comunicação: sintoma da cultura. São Paulo: Paulus.

Santos, L. N. (2008). Corpo, gênero e sexualidade: educar meninas e meninos para além da homofobia. 2008. 136 f. Dissertação (Mestrado em Educação Física). Universidade Federal de Santa Catarina, Florianópolis.

Silva, A. M. (2001). Corpo, ciência e mercado: reflexões acerca da gestão de um novo arquétipo da felicidade. Autores Associados: Editora da UFSC.

Silva Junior, P. M. \& Caetano, M. (2017). Narrativas em primeira pessoa: experiências docentes, gênero e sexualidades. Periferia: Educação, Cultura \& Comunicação, 9(2), 38-58. Disponível em: https://www.e-publicacoes. uerj.br/index.php/periferia/article/view/29379.

Silva Júnior, J. A. (2016). Torcer, retorcer, distorcer e destorce: notas sobre futebol, homofobia e pertencimento. II Simpósio Internacional Futebol, Linguagem, Artes, Cultura e Lazer. Disponível em: http://www.gefut.com .br/gefut/images/artigo/files/Anais\%20Simp\%C3\%B3sio\%20Final.pdf

Silvestrin, J. M. P. (2013). Perform (atividade) na escola: reflexões sobre gênero na Educação Física. Dissertação (Mestrado em Educação Física) Universidade Federal de Santa Catarina. Faculdade de Educação Física. Programa de Pós-Graduação em Educação Física, Florianópolis.

Soares, C. L. (2001). Educação Física: raízes européias e Brasil. 2 ed. Campinas: Autores Associados.

Soares, C. L. (2003). Do corpo, da Educação Física e das muitas histórias. Movimento, 9(3), 125-147.

Soares, C. L. (2011). As roupas nas práticas corporais e esportivas: a educação do corpo entre o conforto, a elegância e a eficiência (1920-1940). Campinas: Autores Associados. 
Souza, C. A. M. \& Vaz, A. F. \& Bartholo, T. L. \& Soares, A. J. G. (2008). Difícil reconversão: futebol, projeto e destino em meninos brasileiros. Horizontes Antropológicos, 14(30), 85-111. Disponível em: https://www.scielo.br/sci elo.php?script $=$ sci_arttext\&pid=S0104-71832008000200004.

Veiga-neto, A. (2008). Dominação, violência, poder e educação escolar em tempos de Império. In: Rago, M. \& Veiga-neto, A. (Orgs.). Figuras de Foucault. 2. ed. Belo Horizonte: Editora Autêntica.

Welzer-lang, D. (2001). A construção do masculino: dominação das mulheres e homofobia. Estudos Feministas, 9(2), 460-482. Disponível em: https://w ww.scielo.br/pdf/ref/v9n2/8635.

Zoboli, F. (2012). Cisão corpo/mente: espelhos e reflexos nas práxis da educação física. São Cristóvão: Editora UFS.

\section{Notas}

1 Os Parâmetros Curriculares Nacionais (1997) é o único documento "oficial” que oferece a possibilidade de ministrar de forma interdisciplinar os conteúdos de gênero e sexualidade na escola. Vale lembrar que ele é apenas um parâmetro e não uma diretriz curricular. Na época escolar relatada, ano de 2002, somente a professora de Ciências ministrava conteúdos relacionados e restritos ao funcionamento anatomo-fisiológico do corpo humano.

2 Em respeito às normas de formatação, grafamos o sobrenome em maiúsculo. Contudo, é importante pontuar que a autora se posiciona politicamente em escrever seu nome em letra minúscula para dar destaque ao texto e à mensagem.

3 "O abjeto é algo pelo que alguém sente horror ou repulsa como se fosse poluidor ou impuro, a ponto de ser o contato com isso temido como contaminador e nauseante" (Miskolci, 2012, p. 43).

4 O único documento (PCN, 1997) que trazia a possibilidade dessas discussões na escola foi violado pelo Ministério da Educação (MEC), em sua página oficial, ao ser retirado do seu texto o volume 10, que trata da Pluralidade Cultural e Orientação Sexual, como pode ser consultado no link: http://po rtal.mec.gov.br/seb/arquivos/pdf/livro07.pdf. Outras fontes que analisam as disputas e a supressão dessas discussões nos documentos regulatórios e sua relação com o campo da EF, podem ser lidas em: Nicolino $(2018 ; 2020)$ e Devide (2020).

5 "As manifestações de sexualidade afloram em todas as faixas etárias. Ignorar, ocultar ou reprimir são as respostas mais habituais dadas pelos profissionais da escola. Essas práticas se fundamentam na idéia de que o tema deva ser tratado exclusivamente pela família. De fato, toda família realiza a educação sexual de suas crianças e jovens, mesmo aquelas que nunca falam abertamente sobre isso", assim como a escola. (Orientação sexual, PCN, p. 77. Disponível em: h ttp://portal.mec.gov.br/seb/arquivos/pdf/livro102.pdf).

6 Importante ressaltar que propositadamente este artigo procura costurar uma narrativa autobiográfica, ou melhor, uma escrita de si (Foucault, 2004) e, por isso, possui uma pluralidade de vozes. Essa escolha reforça que há hoje uma tentativa explícita de se colocar a/os pesquisadora/es mais próximos com o objeto a ser tratado. Subvertendo, de certo modo, a construção distante que se pressupóe uma pesquisa.

7 "Ragatanga" (Asereje) é uma versão em português da música espanhola cantada pelo grupo Las Ketchup. No Brasil, no início dos anos 2000, o single foi responsável pelo sucesso do grupo pop feminino Rouge. A versão do grupo Rouge encontra-se disponível em: https://www.youtube.com/watch?v=fna mLZb9itw.

8 Entendendo dispositivo "inscrito em um jogo de poder, estando sempre ligado a uma ou a configurações de saber” (Foucault, 1979, p. 246), a 
heterossexualidade é compreendida como um dispositivo, por constituir uma rede de saber-poder, que se exercita continuamente de forma heterogênea, verificada em discursos, práticas, modos de se portar, compreender, rir, calar, que se exercitam cotidianamente nas recorrências dos atos de reforçar uma suposta heterossexualidade natural e os estereótipos de gênero, "invisibilizando a homossexualidade e compondo uma equação poderosa para a manutenção das normas de gênero e de sexualidade” (Gonçalves \& Pinto \& Borges, 2013, p. 52).

9 Segundo Carmen Soares (2003; 2011, p. 133), a noção de educação do corpo compreende "inúmeras possibilidades de pensar nos modos como os corpos são educados”, em uma prática que opera tanto no corpo individual quanto na coletividade, quando tornada hábito. Assim, no 'país do futebol' e, sobretudo, em tempos de Copa do Mundo entendemos haver um investimento sobre e pelo corpo em suas potencialidades física, emocional e moral das pessoas que se submetem ao 'jogo'.

10 Cientes da existência de diversos discursos na EF que buscam ultrapassar as explicações naturalizantes do movimento humano e concebem o objeto da Educação Física como fenômeno cultural (Mendes \& Nobrega, 2009), optamos pelo termo 'cultura corporal', desenvolvido pelo Coletivo de Autores (1992, p. 26 e 33), pela proposição pedagógica crítica que estabelece no âmbito escolar, ao tematizar "formas de atividades expressivas corporais como: jogos, danças, lutas, exercícios ginásticos, esporte, malabarismo, contorcionismo, mímica e outros",(...) como conteúdos a serem desenvolvidos por meio da "noção de historicidade retraçando-o desde sua gênese, para que este aluno se perceba enquanto sujeito histórico. Essa compreensão é básica para a concretude do currículo".

11 A compreensão de violência aqui utilizada alinha-se ao conceito de homofobia desenvolvido por Daniel Borrillo (2010), que o traz como um fenômeno complexo, operacionalizado, muitas vezes, pela invisibilidade cotidiana compartilhada pela indiferença, inferiorização, desumanização e distanciamento do homossexual (homens e mulheres), com a finalidade de destitui-lo de humanidade e de seus plenos direitos.

12 Paul Preciado (2020) analisa as 'falências' de controle e opressão exercidos sobre os corpos em tempos de pandemia, de modo a questionar o quanto o corpo individual é um espaço vivo e uma trama de poder, um novo território de projeção de políticas agressivas de fronteira, expressas agora sob a forma de uma barreira e guerra contra o vírus.

13 Em um contexto marcado pela abertura democrática do país, o campo acadêmico da EF iniciou, na década de 1980, discussões sobre os objetivos e os conteúdos da área, em discordância com os termos postos até então. Esse momento ficou conhecido como Movimento Renovador da EF, segundo Medina (1986), Ghiraldelli Junior (1989) e Castellani Filho (1994).

14 Entendemos, como Butler (2019, p. 219), que há em nossa cultura uma "falsa ideia de 'homem' universal como sinônimo de humanidade", que segundo Louro (2001, p. 15-16), "remete ao homem branco, heterossexual, de classe média urbana e cristão (...). Serão os 'outros' sujeitos sociais que se tornarão 'marcados', que se definirão e serão denominados a partir dessa referência. Desta forma, a mulher é representada como "o segundo sexo" e gays e lésbicas são descritos como desviantes da norma heterossexual".

15 Algumas referências que tratam sobre o tema: Alliatti, 2014; Bandeira, 2016; Franzini, 2005; Observatório, 2018; Silva Júnior, 2016. 